\title{
Cultivation of Non-English Majors Intercultural Awareness via Appreciating Oscar Best Pictures
}

\author{
Huijian Wang, Ying Huang, Lei Dong \\ College of Foreign Language Education and International Business, Baoding University, Baoding, China \\ Email: lanyu2003flower@163.com
}

How to cite this paper: Wang, H. J., Huang, Y., \& Dong, L. (2021). Cultivation of Non-English Majors Intercultural Awareness via Appreciating Oscar Best Pictures. Creative Education, 12, 1655-1665. https://doi.org/10.4236/ce.2021.127126

Received: June 5, 2021

Accepted: July 24, 2021

Published: July 27, 2021

Copyright (๑) 2021 by author(s) and Scientific Research Publishing Inc. This work is licensed under the Creative Commons Attribution International License (CC BY 4.0).

http://creativecommons.org/licenses/by/4.0/

\section{(c) (i) Open Access}

\begin{abstract}
Language is the carrier of culture. Mastering a language is not only to learn the language itself, but to learn and understand the cultural elements that the target language embodies. College English teaching should make great effort to introduce cultural knowledge to enhance students' intercultural awareness, which is the basis of students' intercultural communicative competence, and intercultural communicative competence is the reality of students' intercultural awareness. As means of teaching, film plays an important role in cultivating students' cultural awareness, especially inter-cultural awareness. This thesis adopts methods of literature to carry out research on Oscar Best Pictures and advantages of appreciating them in non-English Majors' culture learning and cultivating their inter-cultural awareness. The author hopes this exploration will arouse college English teachers' and non-English majors' thinking and attention to English culture learning and cultivation of intercultural awareness and promote more further study.
\end{abstract}

\section{Keywords}

Cultivation, Intercultural Awareness, Oscar Best Pictures

\section{Introduction}

Language and culture are inextricably linked: the language itself is a product of culture, specific language is always rooted in a particular cultural soil; language is the carrier of culture, which reflects the culture while is constrained by the culture. Mastering a language is not only to learn the language itself, but to learn and understand the cultural elements that the target language embodies.

The College English Teaching Guide (2020) points out: one of the teaching 
objectives of College English is to cultivate students' application ability, enhance inter-cultural awareness and competence, getting students capable of using English appropriately and effectively in study, life and future work. This indicates that the College English Teaching is not merely to understand the surface meaning of voice, vocabulary and grammar, but also to give full consideration to impart cultural knowledge to the students. In intercultural communication, language learners and users have to understand the cultural system that the target language carries and learn about how the speakers of the target language look at things, how they observe the world, and how they use the language to reflect their thoughts and behavior, thus the learners and users can select the appropriate language and expression according to different cultural background, attaching more importance to smooth and authentic language activities than the accurate and complete expression of language, stressing the successful communication through language more than the practice of language itself, to achieve the purposes of effective communication. Therefore, language teaching is not only the teaching of the language itself; it should also include cultural teaching.

This study aims to explore the practical significance of appreciating Oscar best Pictures in non-English majors' cultural learning and cultivating their intercultural awareness in the process of college English teaching.

\section{Literature Review on Oscar Best Pictures}

As the topic of this thesis is primarily on the effects of Oscar Best Pictures appreciation on Chinese non-English majors' intercultural awareness, this literature review will include those researches on Oscar Best Pictures both in China and other countries.

There are several monographs about Oscar, two of which are polarized on this award. One is authorized and recognized by Motion Picture Arts and Sciences (AMPAS), edited by Robert Osborne, Oscar Seven Decades: Academy Awards Official History, in chronological order, photographed countless photos and texts, recording the film industry in seven decades and the awarding ceremonies, achievements, development trends of Oscar as well as major events. Osborne also made comment on the most sensational movie and shared a lot of behind-the-scenes stories with readers, which let the readers feel like immersed in grand awards ceremony. This book contains all the Oscar nominees and winners, and also specifically lists the record holder of the Oscar. With its deep reports and authority, it attracts movie lovers all around the world.

Another is, without authorization and approval of the college, "Oscar Insider: Academy Award Gaishi", by Mason Willie and Damin Bona. The little-known insider revealed was thought highly of by the U.S. media and academic; Ann Sarris, a famous film theorist, said that the book was a very useful sociological and aesthetic guide to know about Hollywood over the last 60 years.

Meanwhile, there are many review articles for the Oscar-winning films in China. These researches are roughly divided into the following categories: 


\section{1) Overview of Oscar}

Wang Wei (2006) and Kang Ni (2006) both stated the history, the composition, the procedure and the rules of the Academy Awards, and gave some brief introduction of Oscar-winning films. Among these findings, their introduction about the history of the Academy Awards, the composition, the basic content of the awards program is much the same, but there are a number of different voices on the evaluation rule.

2) Specific comments on Oscar-winning film, director, actors and actresses

Most papers belong to this type, such as Jiang Dong and Li Chao's "Oscar Grand”, Yan Min's (2008b) “The Oscar Awards: Legend of 80 Years", Liang Liang's (2003) "Dating with Oscar (Academy Award-winning Film Notes)" and so on, most of which are papers or monographs of critic style on a winning film, such as "Analysis of" Forrest Gump' from the Ideological Perspective" written by Li Yanling (2008), The Ideological Analysis of 'Crash' by Zhang Bin. In addition, there are lots of researches on the famous directors' and actors' treatises such as, Xu Yayue's (2007) “Ang Lee's Oscar Dreams” and so on.

3) Comprehensive study of macroscopic phenomena

Yan Min (2008a) did some macro analysis and drew conclusion that the previous Oscar Best Pictures always have their profound intrinsic value, closely relate to modern life and people's needs and can get the audience's wide resonance.

4) Research on Oscar related politics, commerce and culture

Studies on Oscar are not limited to the scope of artistic phenomenon, but also involve political, cultural and commercial factors, such papers came into being, such as Political Responsibility of Oscar Award (Xie, 2007), Research on the Theme Features of Oscar Best Pictures of this Century (Cai, 2014) and Analysis of the Mainstream Values of Oscar Best Pictures (Wu, 2017).

\section{5) Aesthetic research on Oscar Best Pictures}

An Aesthetic Research of Oscar Films, written by Xu Yusi (2009), analyzed the mainstream values demonstrated in Oscar films from four areas: freedom, humane, personal heroism and indomitable faith, and analyzed the way of artistic expression, making reference for Chinese film making.

To sum up, researches on Oscar Best Pictures are mostly analysed and theoretical researches from the perspective of film comment, and there are few systematic research papers or monographs discussing the importance and advantages of Oscar Best Pictures in cultivating non-English majors' intercultural awareness. Therefore, it is a new research that is worth doing to combine the appreciation of Oscar Best Films and cultivation of non-English majors' intercultural awareness.

\section{Significance of Intercultural Awareness}

\section{Definition of IA}

Intercultural awareness is a quality that enables people to achieve a multicultural 
mind-set. It covers both the target culture (C2) and the native culture (C1), it especially focuses on how $\mathrm{C} 2$ relates to $\mathrm{C} 1$. It involves interactions among people from different cultures: it means some sort of 'sensitivity and understanding', which intends to internalize the values of the 'other' culture and learn from it while trying to adapt oneself to it and is an internally directed and mind-change issue. It demonstrates itself in knowledge, feelings, attitudes and behaviors that one would consciously experiences, recognizes and reflects in any real or potential intercultural interactions.

From the psychological point of view, intercultural awareness is the way we respond to differences. It consists of three perspectives, as follows:

1) Affective Perspective-How we feel about and evaluate people who are different from us.

2) Behavioral Perspective-How we behave toward people who are different from ourselves and how we exercise power, the assumptions people make about power and privilege.

3) Cognitive Perspective-How we think about people who are different from ourselves.

\section{Significance of IA Cultivation in English Teaching}

With the globalization and the rapid development of information technology, the intercultural communication between China and other countries is more and more frequent. China is in urgent need of talented persons that have solid professional knowledge and can directly communicate with English native speakers of investors, foreign experts and other personnel, which are talents of expertise + intercultural communication competence.

Due to various reasons, although, many non-English major graduates passed CET4 or CET6, they cannot meet requirements of society. Their English expressions are often affected by Chinese way of thinking, and in conversations with foreigners they cannot express themselves in appropriate English, which often leads to misunderstanding and displeasure. So, cultures of both sides must be taken into consideration. They should understand how the native speakers of the target language use it to reflect their thoughts, behaviors and habits. Successful intercultural communication depends not only on language proficiency, but more on the level of understanding of the target language culture. Intercultural communication won't happen if the two sides of communication cannot share the same cultural background. So only when they regard cultural background and cultural knowledge as important bases for their thinking, can students know why and what to say. Only in this way, can they effectively avoid communication barriers.

Intercultural Awareness is the basis of students' intercultural communicative competence, while intercultural communication competence is a concrete manifestation of intercultural awareness in reality (Zhao, 2010). Only when a person has a certain degree of awareness of intercultural communication, can he 
possibly turn this awareness into intercultural communication capabilities in intercultural communication activities. So cultivation of intercultural awareness must be included in college English teaching. On this basis, the language learners can consciously and independently compare the target language culture with native cultures to identify the differences, transport the learned language knowledge and language skills more accurately and properly and develop good study strategies and emotional attitude, and all of which are good for achieving the purpose of English teaching. Therefore, the cultivation of intercultural awareness is conducive to the smooth progress of college English teaching and is an important way to improve the quality of college English teaching.

\section{Advantages of Oscar Best Pictures in IA Cultivation}

Its cultural connotations and artistic trends of Academy Award keenly represent the trend of globalization. With continuous development, it has become the most coveted film awards among the film makers in the world. It is an award with great popularity and the most extensive audience, which is not just limited to Americans; Oscar Best Pictures are not only American-involved films; it absorbs film talents from all over the world blending naturally global cultures; it concerns global hot spots and focuses on social cultural trend from a Western perspective. With their unique aesthetic value and cultural identity, Oscar Best Pictures are more effective than textbooks, literature and other written and listening materials used in cultivating college students' intercultural awareness.

\subsection{Great Popularity and a Most Extensive Audience in the World}

Films are composed of interrelated visual episodes that tell a story together. Since their birth, films have enjoyed great popularity among people on account of their different forms of expression. They can satisfy many different needs, such as entertainment, artistic appreciation and self-expression.

The Academy Award is the Nobel Prize of the film industry. Among numerous film awards in the world, it is undoubtedly the award of great influence, the highest gold content, and with the longest history and the greatest popularity. There will be more than 200 million people watching the live performances of annual awards ceremony for the world and a myriad of stars from all over the world arrive here to attend this event. Reviewing the Oscar's 93 years of history, people will see the progress of film art and Oscar's important position in film industry. It has become the most coveted film awards of world's movie-participants makers.

Generally, it is believed that film art is born a popular art because of its unmatched realistic visual and auditory effect and the zero-distance obstacle between film and the construction of social reality. This inherent advantage decides that this kind of art has the greatest potential audience. And Oscar can maximize this inherent advantage. According to statistics, due to the Oscar Effect, since the nomination of Oscar best film, the box office rebounded to dif- 
ferent degrees. Once Nielsen's survey showed that the nomination of best picture can enhance its box office of $\$ 6.9$ million and the winner of best picture box can increase its box office of $\$ 18,100,000$ on average.

In addition, the famous research institution-Box Office Mojo.com-has the box office records on previous Oscar Best Pictures. According to the data, the author lists statistics of the box office of top 15 , including domestic and foreign box office.

Although the box office data cannot fully represent the exact number of the Oscar audience, the above figures show that the Oscar Best Pictures, with good reputation, have a broad impact and extensive audience both in the United States and foreign countries.

\subsection{Internationalization}

About the internationalization of Oscar Best Pictures, it mainly includes three aspects: the background of Oscar Best Pictures, the locations of film shot and awarded works.

\section{1) Background}

Among 93 Oscar Best Pictures, the background is related to the 16 countries, such as United States, Britain, France, Germany, Austria, Africa, India, China, Korea and so on. There are 36 films that adopted two or more languages, including 7 films which adopted four languages. In these films, the filmmakers interpreted the world from different perspectives.

First, viewing the U.S. with American perspective: Among 93 Oscar Best Pictures, about 47 Hollywood films reflect the native American life, such as The Broadway Melody, Cimarron, It Happened One Night, The Great Ziegfeld, You can't Take, Gone with the wind, The Lost Weekend, Best Years of Our Lives, Golden Age, West Side Story, Ordinary People, Driving Miss Daisy, American beauty, No Country For Old Man The Sting, Crash and so on. Hollywood filmmakers interpret the mainstream values advocated by the U.S. from American perspective. Humanism, heroism and faith of life-long struggle for freedom, ideals, science and truth are vividly reflected in films.

Second, viewing the western countries from American perspective: in some Hollywood productions of non-national content which reflect background of other countries such as Britain, France, Germany, Austria and so on, the filmmakers introduce the Western world from American perspective, taking the American in Paris, The sound of Music, Munity on the Bounty, Schindler's List and Casablanca for example, although they make use of foreign themes, they, in fact, pay attention to the future of marketing and cultural transmission.

Third, viewing Eastern countries from the perspective of Westerners. The Last Emperor and Slumdog Millionaire are classic models, which are two Western films about Eastern countries. The Last Emperor is the first western movie on China since 1949, which got the full cooperation of the Chinese Government. It is a co-production by France, Britain, Italy and China. The writer and director 
focus on AIXINJUELUO Puyi-the last emperor of feudal dynasty in China and his story from a pure westerners' perspective. In their eyes, Puyi is just an individual in a particular historical condition who cannot escape the fate of the imprisoned life and he is a man of complicated composition and faceless with which the audience can communicate in emotion. They are completely different from serious and cautious Chinese who thinks that storytelling and history are completely different and the deal of details should respect the truth of history.

Slumdog Millionaire is adapted from Indian writer Vikas Yeshiva Loop's works " $Q \& A$ ", directed by British director Dan Benny Boyle, which was released in 2008. It describes a young man from the slums, who participates in a quiz show named "Millionaire" and goes on very smoothly to be the winner. But the host suspects him of cheating. In police torture, he tells stories of the past events related to the topic. Someone thinks it is not a true description of India, but the Western countries' distortion and control of the oriental culture in the post-colonial era, so as to satisfy Western audience's psychological adventures, to meet Western Orientalists' particular taste, reflecting the unequal relationship of cultural discourse between the suzerain and the colony in post-colonial period.

\section{2) Locations of film shot}

The vast majority of the Oscar Best Pictures are shot outside the United States, which shows the improvement of international filmmaking level, but also blurs the definition of the so-called Hollywood movies. In fact, the American Beauty (1999) was the only one completely shot in Hollywood since 1976.

\section{3) Awarded works}

In 1929, Academy of Motion Picture Arts and Sciences Academy strictly limited Academy Awards to the United States. In the first few decades, Oscar had always been dominated by Hollywood and Hollywood became synonymous with world film, it was almost all Hollywood filmmakers that were able to board the Oscar podium. Rarely did any foreign works break the monopoly of Hollywood movies. But the next few decades, a lot of innovative films were from overseas markets. As early as the 69th Oscar, when The English Patient won the Best Picture Award, there was someone proposing "internationalization". It was taken for granted that it wouldn't be overstated that British and Australian works won the prize. Now, filmmakers from India, France and other countries will leisurely build momentum and spread their culture to the world with the platform of Oscar.

Oscar is now becoming synonymous of international film awards. The college makes efforts to build it as the world's first award in film industry and the intention is clear enough. Thus, series of non-US works and filmmakers won the awards and would be the ultimate beneficiaries, which could stimulate the film industry in their countries, bringing about global impact on economy and cultures. Therefore, it is not difficult to understand, an Indian story Slumdog Millionaire, invested and made by the British, was greatly successful in the United States, and thus became hot all around the world, which in itself is a process of 
internationalization with the style of American dream. Its internationalization has already infiltrated into every aspect of the film, the most critical of which is the theme of a movie demonstrated with diverse cultural elements.

The internationalization of Oscar Best Picture itself is a kind of communication and collision between cultures and this inclusive spirit is worthy of students' learning and training in intercultural communication.

\subsection{Realistic Concern}

If observe all results of previous Oscar Best Pictures on the course of history, it can be easily discovered that these movies can widely resonate with the audience. Because they are always keen to reflect contemporary trends and mass's psychology and they can provide the audience a timely beacon or spiritual sustenance. So it has the characteristic of a high degree of realistic concern. For example, after the World War II, a variety of maladaptive problems appeared when American society was rebuilt. Then the Oscar elected successive films about social problems and awarded them Best Pictures, in turn, they are: The Lost Weekend (1945) to discuss alcoholism problems, Best Years of Our Lives (1946) reflecting the demobilization of veterans, Gentleman's Agreement (1947) criticizing anti-Semitic phenomenon. These award-winning films were not necessarily the best competing films in arts, but they were the closest to social atmosphere and the topic which the audiences were concerned about, so they outstood and became a way that American filmmakers expressed their social concern by Oscar activities. Hollywood, to meet the audience's psychological need of "dream hunting", sometimes woke the audience to care about their own society.

At the beginning of 1970s, gang crime and drug problems became increasingly rampant social issues in American society, Oscar awarded four consecutive Best Pictures to: gangster movie The French Connection (1971) in which detectives hunted down drug dealers, epic movie The God father (1972) about mafia family crime, crime comedy The Sting (1973) about battle of wits between Stings, the sequel The God Father II (1974) that the second generation of the mafia family intended to corporatize the crime. Such awards results clearly reflected the level of socialization of Academy Award. To the alternating moments of 1970s and 1980s, "new feminism" flourished in the United States. Women's consciousness of economic independence and the pursuit of self was improved, which had brought a lot of impact on the family system in the United States. Then there appeared Kramer vs Kramer (1979) and Ordinary People (1980).

These two pieces of movies about family problems led the audience attach importance to family crisis, playing functions of edutainment and social education. And after the "Yuppie Fashion" and "Brand-name consumer fever" in 1980s, the American public had a new psychological need of "Mental green" with the era of economic downturn and transferred from the pursuit of external material needs to spiritual reflection. So, western on the behalf of American history and tradition again were attached importance to, such as Dances with 
Wolves (1970) atoning to minorities for the whites, and anti-hero western $U_{n}$ forgiven (1992) that fought for human dignity for ordinary people were awarded Oscar Best Pictures. In this new era, the hero turned out to be as simple mentality and single-mindedness of thoughts and feelings as mentally retarded Forrest Gump. When Forrest Gump (1994) won Oscar Best Picture, some people criticized that Oscar was too conservative, not knowing this is a "neo-conservative" era. While "conservative" is the contemporary mainstream of American popular thinking. The reason why Forrest Gump caused the majority of audience's resonate is that it accurately grasped the pulse of the times. It created a successful box office of more than three hundred million U.S. dollars in the United States. Oscar to movies is like fuel to the flames. But in fact, it helps when movies follow the times and obtain general audience's recognition.

Mainstream movies should keep the presence of the audience in mind at any time. Oscar accurately reflects the needs of the audience and also receives wide recognition of the audience. As the "reader response theory" says: "The value of literature does not objectively exist in the works itself, but in the readers' response to works." So do the value of mainstream movies.

\subsection{Literariness}

Literariness means the quality of being literary. Literary and film contact or combine more intimately. Film refers and draws up from literary a lot. Film learns from literary very important things such as lyric of poetry, documentary of prose, narration of fiction and conflict of dramatic literature. Literary lays the most solid foundation for films. Films present the unique beauty of language, beauty of painting, beauty of architecture etc. in literature vividly, which can make readers feel literary more intuitively and understand the essence of literary.

Looking at the 93 Oscar Best Picture, the most profound feeling is that literature and Oscar have a deep bond and literature has a growing impact on movies. According to 2011 U.S. online magazine "The Huffington Post" statistics, since 1930, 25 films that were adapted from literature works won the Oscar Best Pictures. For example, The Silence of the Lambs (1991) was adapted from the American writer Thomas Harris's novel with the same name; Schindler's List (1993) was adapted from the Australian writer Thomas Ken Nil's novel "Schindler's Ark'; Brave Heart (1995) was adapted from American writer Randall Wallace's novel with the same name; The English Patient (1996) was adapted from the Sri Lankan-Canadian writer Michael Ondaatje's novel with the same name; No Country for the Old Men (2007) was adapted from American's famous writer Cormac McCarthy's master novel with the same name, who has ever won the Pulitzer Prize for literature; Slumdog Millionaire (2009) was adapted from the Indian writer Vikas Svalbard Loup's novel " $Q$ \& A"; and King's Speech (2011) was adapted from the English writers Roger and Kang Ladi's novel with the same name. Literariness of Academy Award re-evokes readers' sense of reading 
classics and plays an important role in cultivating readers' humanities, promoting wisdom, moral enlightenment and ideological indoctrination.

\section{Conclusion}

College English teaching should focus on language teaching from a cultural perspective to input cultural knowledge step by step, increase the input of English cultural knowledge in the ordinary course of English teaching and make great effort to introduce cultural knowledge to enhance students' intercultural awareness which is the sensitivity of similarities and differences between the exotic culture and native culture and let them adjust their own consciousness of language comprehension and language production according to the target language culture (such as English), which is the sensitivity of feeling, the appropriateness of processing and consciousness of cultural integration. In other words, in the process of foreign language learning, students should know how the native speakers of the target language use it, such as what they talk about, how they talk, what communicative means they use, what kind of social and cultural information contained in the forms of language and methods of communication they use, so that the students can overcome the pragmatic failure and misunderstanding caused by the lack of cultural background knowledge in intercultural communication. Therefore, intercultural awareness is the basis of students' intercultural communicative competence, and intercultural communicative competence is the reality of students' intercultural awareness. Only when a person has a certain amount of intercultural awareness, can he convert this kind of awareness into intercultural communication ability and succeed in effective cross-cultural communication.

Oscar Best Pictures, with their unique aesthetic value and cultural identity, show the artistic styles of different ethnic groups. As teaching resources, they are more effective than textbooks, literature and other written and listening materials, because the diversified technical factors enhance the charm of the Oscar movies. They have greater visual impact and attractiveness to college students because they are perfect artistic combination of audio, video and culture. Appreciating Oscar Best Pictures can not only cultivate college students' English thinking and the ability to convert language knowledge, but also can gradually develop students' ability to feel, understand, judge and appreciate, strengthen students' understanding of culture, history, religion, customs and other aspects of English-speaking countries, stimulating college students' interest in English learning. So it is of great benefit to enhance students' comprehensive cultural literacy and to cultivate students' intercultural awareness in different cultural backgrounds.

\section{Conflicts of Interest}

The authors declare no conflicts of interest regarding the publication of this paper. 


\section{References}

Cai, M. N. (2014). Research on the Theme Features of Oscar Best Pictures of This Century. Hebei University.

Kang, N. (2006). Identifying the Oscars. Movie, 4, 8-9.

Li, Y. L. (2008). Analysis of "Forrest Gump" from the Ideological Perspective. Movie Review, 12, 45-47.

Liang, L. (2003). Dating Oscar. Guangxi Normal University Publishing.

Wang, W. (2006). Viewing Oscar. Movie Review, 10, 33.

Wu, X. G. (2017). Analysis of the Mainstream Values of Oscar Best Pictures. Movie Literature, $13,60-62$.

Xie, Y. Q. (2007). Political Responsibility of Oscar Award. South Reviews, 6, 81-82.

Xu, Y. S. (2009). An Aesthetic Research of Oscar Films. Hunan Normal University.

Xu, Y. Y. (2007). Ang Lee's Oscar Dreams. Mental World, 4, 13.

Yan, M. (2008a). Oscar in Academic View. Arts Criticism, 4, 12.

Yan, M. (2008b). The Oscar Awards: Legend of 80 Years. Wenhui Press.

Zhao, B. H. (2010). How to Enhance Cross-Cultural Awareness in TEFL. Cross-Cultural Communication, 6, 100-104. 